\title{
A comparison of the leaf gel extracts of Aloe ferox and Aloe vera in the topical treatment of atopic dermatitis in Balb/c mice
}

\author{
M. J. Finberg ${ }^{1}$; G. L. Muntingh ${ }^{1}$; C. E. J. van Rensburg $2^{\star}$
}

* C. E. J. van Rensburg

connie.medlen@up.ac.za

${ }^{1}$ Department of Pharmacology, School of Medicine, Faculty

of Health Science, University of Pretoria,

Prı́vate Bag X323, Arcadia, Pretoria 0007, South Africa

${ }^{2}$ Office of the Dean, Faculty of Health Science,

University of Pretoria, Prívate Bag X323, Arcadia,

Pretoria 0007, South Africa

\begin{abstract}
Aloe vera gel is widely used in the treatment of an array of disturbances, especially skin disorders. The woundhealing effects have been attributed to its moisturiz-ing and anti-inflammatory effects as well as its beneficial effect on the maturation of collagen. The aim of the present study is to compare the effects of topically applied extracts of Aloe ferox with that of Aloe vera on the symptoms as well as $\operatorname{IgE}$ levels of a mouse model of atopic dermatitis (AD). Mice were sensitized and challenged with 2,4-dinitrochlorobenzene and treated afterwards for 10 consecutive days with the gels of either A. ferox or A. vera applied topically to the affected areas. A placebo gel was used for the control mice. Blood was collected at the beginning and end of the treatment period to measure serum $\operatorname{IgE}$ levels. Although the gels of both the Aloe species inhibited the cutaneous inflammatory response as well as serum $\mathrm{IgE}$ levels in the rats, the extracts of A. ferox were superior to that of A. vera in reducing IgE levels. The gels of A. ferox and $A$. vera, applied topically, may be a safe and useful alter-native to antihistamines and topical corticosteroids, for the treatment of patients suffering from recurring chronic AD.
\end{abstract}

Keywords Atopic dermatitis - Topical treatment . Aloe ferox. Aloe vera

\section{Introduction}

Atopic dermatitis (AD) is a chronic relapsing cutaneous disease characterized by dry and scaly skin, inflammation, and intense itching (Ellis et al. 2003). It affects up to $20 \%$ of children in developed countries (Ashcroft 2005). A worldwide increase in the incidence of atopic diseases has been documented as far back as 1999 (Beltrani 1999). AD is associated with early IgE (immunoglobulin E) production and allergen/ $/ \mathrm{IgE}$ reactivity and is characterized with itching, inflammation, and an exudation (Ellis et al. 2003). It has been suggested that there is a link between atopic dermatitis, asthma and allergic rhinitis (Ellis et al. 2003). Current topical and systemic treatments for AD are reasonably effective but are associated with inconvenient side effects. The first-line treatments for the symptoms of $\mathrm{AD}$ are antihistamines and topical corticosteroids. However, antihistamines are associated with various side effects, the most serious of which is their sedative potential (Kay 2000). Topical corticosteroids, on the other hand, are associated with side effects such as atrophy, rosacea, acne, purpura, hyperglycaemia, glaucoma, perioral dermatitis and purpura (Arellano et al. 2007; Henge et al. 2006). Systemic application of corticosteroids is effective in relieving the symptoms of AD but can only be administered once or twice annually because of long-term side effects such as osteopenia and cataracts (Sidbury and Hanifin 2000). There is therefore an urgent need for the development of effective but safer treatments for atopic dermatitis.

The genus Aloe is used traditionally for the treatment of an array of disturbances ranging from anorexia, dyspepsia, constipation and diseases of the liver, hypochondria and mania (Capasso et al. 1998). It is a tropical/subtropical plant and has been used in the cosmetic as well as 
pharmaceutical industry for skin disorders such as wounds and radiation damage and as moisturizing and antiseptic agent for many years (Eshun and He 2004). The clinical use of the gel began in the 1930s, with reports of successful treatment of X-ray and radium burns, which led to further experimental studies using laboratory animals in the following decades. Kim et al. (2010) compared the effects of oral extracts of Scutellariae radix and Aloe vera on $\mathrm{AD}$ induced $\mathrm{NC} / \mathrm{Nga}$ mice. Both these treatments suppressed IL-5 and IL-10 levels in mice. On the other hand, the extracts of $A$. vera caused an increase in IgE levels.

Aloe ferox is indigenous to South Africa. The medicinal properties of A. ferox have been extensively reviewed by Chen et al. (2012) and Eshun and He (2004). It has been described as an anti-oxidant with anti-inflammatory, antifungal, anti-cancer, anti-bacterial, anti-malarial and wound-healing properties (Reynolds and Dweck 1999). The inner leaf pulp or leaf gel contains polysaccharides and various phenolic phytochemicals such as alkaloids, columarins, anthrones, and phenolic phytochemicals (Cock 2015). It is used as an oral treatment for infections, inflammation, cancer and malaria as well as topically applied for skin ailments. The extracts contain carboxypeptidase, bradykinase and aloeresin-I, all of which have been shown to relieve pain and decrease inflammation and swelling (Duke 1997). The leaves and roots have been applied topically to treat dermatitis and eczema as well as skin cancer, psoriasis and burns. The wound-healing effects have been attributed to its moisturizing and anti-inflammatory effects as well as its beneficial effect on the maturation of collagen (Chen et al. 2012).

Kim et al. (2010) studied the effects of extracts of $A$. ferox and $S$. radix, applied systemically, on $\mathrm{AD}$ mice. Although both these extracts had no effect on the symptoms of the disease, extracts of $A$. ferox caused an increase in serum IgE levels and a decrease in Il-5 and Il-10 levels.

Up till now, no research has been done to determine the effects of the gels of A. vera and A. ferox, applied topically, on $\mathrm{AD}$. In this study, $\mathrm{AD}$ was induced in mice with the topical application of 2,4 dinitrofluorobenzene (DNFB) on their right ears after which they were treated topically with either a placebo gel or with the gels of either A. vera or $A$. ferox. These products are on the market as topical treatment for skin diseases.

\section{Materials}

A $97 \%$ A. ferox gel and a placebo gel were supplied by Alcare Aloe, 39 Industrial Avenue, Albertinia, Western Cape, South Africa, and A. vera gel was purchased from PharmaNatura, Wynberg, South Africa containing $96 \%$ pure extract. Both products were used at the dosages that are presently on the market.

Both products were dissolved in a small volume of acetone and made up to a concentration of $0.25 \%$ in sesame oil. This dilution was decided on as mice could be more sensitive to treatment than human beings. Male $\mathrm{BALB} / \mathrm{c}$ mice weighing between 20 and $40 \mathrm{~g}$ were obtained at 4 weeks of age from the Centre of Animal Services at the University of the Witwatersrand, Johannesburg.

\section{Methods}

This study was done as a double-blind, randomized, parallel-group comparative study over a 15-day treatment period. All mice were coded.

Scientific procedures were strictly adhered to according to the Code of Practice for the Housing and Care of Animals (Acts 1986 and 1989, respectively). Approval was obtained from the Animal Use and Care Committee (animal ethics committee) of the University of Pretoria, South Africa. The mice were housed in plastic containers, 5 per cage, at the University of Pretoria's Biomedical Research Centre in a controlled environment with a temperature and humidity of $23 \pm 2{ }^{\circ} \mathrm{C}$ and $55 \pm 5 \%$, respectively, under 12-h light/dark cycles. They were fed a conventional rodent diet obtained from Epol (Pty) Ltd (Randburg, South Africa) and had an unlimited supply of drinking water. They were allowed to acclimatize for 1 week.

This study was done as a double-blind, randomized, parallel-group comparative study over a 15-day treatment period. All mice were coded. To induce atopic dermatitislike skin lesions, a method described by Lee et al. (2007) was followed.

For this study $60 \mathrm{BALB} / \mathrm{c}$ mice were coded and sensitized. Sensitization was done by spreading a $20-\mu 1$ application of 2,4 dinitrofluorobenzene (DNFB) (purchased from Tocris Japan), dissolved in a small volume of acetone and made up to a concentration of $0.25 \%$ in sesame oil over the right ears of the mice. At the same time $20 \mu \mathrm{l}$ of sesame oil was applied in the same manner to the left ears of the mice. They were then divided into three groups and challenged by repeating the above-mentioned procedure after 7 days and every second day afterwards for the duration of the experiment.

Treatment commenced on day 16 . Both ears of the mice were treated topically by spreading $10 \mu$ of either A. vera gel, A. ferox gel or placebo gel over the affected areas on a daily basis for 10 days.

Mice were monitored for any signs of pain or distress by a qualified veterinarian on a daily basis and would have 
been euthanized if necessary. Ear thickness was measured every second day with an electronic calibre.

Mice were euthanized on day 10 of the treatment procedure by isoflurane overdose and blood was collected by cardiac puncture for serum IgE measurement. Macroscopic photos were taken of the affected areas with a Canon $\mathrm{Cu} 250$ camera. The dorsal skin of each mouse was dissected, carefully removed and placed in $10 \%$ buffered formalin overnight. The sections were progressed according to standard pathological procedures. The section $(3 \mu \mathrm{m}$ thick) were cut, dewaxed and stained with haematoxylin and eosin for histopathological analysis.

\section{IgE levels}

Serum IgE levels were determined by a sandwich enzymelinked immunosorbent assay (ELISA) using a BioLegend's ELISA MAX ${ }^{\mathrm{TM}}$ Deluxe kit.

\section{Statistical analysis}

Results are expressed as mean \pm SEM. Specific differences between study groups, following significance in the ANOVA were obtained using two-group $t$ tests employing the pooled standard deviation determined from within group mean squares. These pair-wise comparisons were done at the Bonferroni adjusted $0.017(=0.05 / 3)$ level of significance.

\section{Results}

\section{Macroscopic results}

Macroscopic photographs were obtained with a Canon $\mathrm{Cu} 250$ camera and an example thereof is presented in Fig. 1. Clear signs of DNBF induced dermatitis can be seen in a placebo-treated mouse (Fig. 1a). Regarding the two treatment procedures (Fig. 1b, c) there were no signs of the disease in the A. ferox treatment arm whereas the mice in the A. vera treatment arm still showed traces of the disease.

\section{Histological results}

Histological findings showed an absence of skin structures such as hair follicles, sweat glands and ulceration in the placebo group, whereas the two treatments resulted in an increase of sub-epithelial stromal cells (Fig. 2).

\section{IgE results}

Serum IgE levels are presented in Table 1. The results indicated that both the active treatments decreased the $\operatorname{IgE}$ levels of the experimental mice significantly, compared to the placebo group [using one-way ANOVA $(p<0.0001)]$. The results obtained with the A. ferox gel treatment were also significantly lower compared to the $A$. vera gel treatment using a pair-wise $t$ test $(p=0.002)$.

\section{Adverse events}

Four mice died during the study. Two were from the placebo group and died because of a severe reaction to the DNFB application and two from the A. ferox group due to fighting.

\section{Discussion}

Atopic dermatitis is a chronic disease that is difficult to define because of its variable morphology and distribution and its intermittent nature. Within the last several decades, there has been enough evidence to support the concept that AD has an immunologic basis (Leund 1997) and is associated with an increase in IgE levels (Stephen et al. 1973).
Fig. 1 Macroscopic photographs of 2,4dinitrochlorobenzene (DNCB)induced skin lesions of atopic dermatitis on mice after a 15-day treatment with a a placebo gel, b Aloe ferox gel and c Aloe vera gel
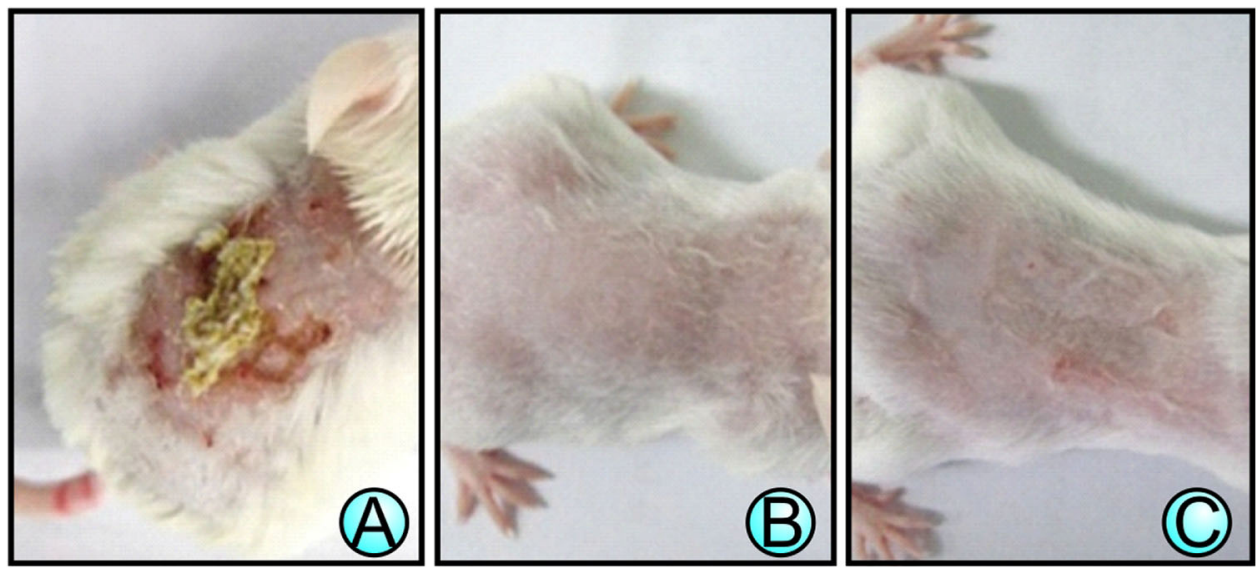

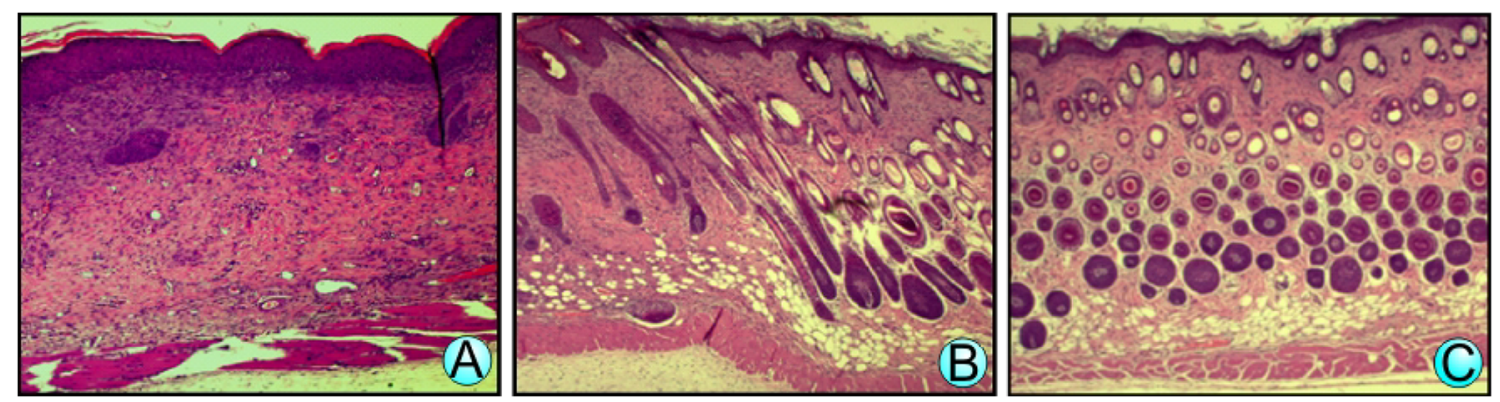

Fig. 2 Microscopic photographs of haematoxylin/eosin-stained sections of skin lesions on mice with 2,4-dinitrochlorobenzene (DNCB)-induced atopic dermatitis after a 15-day treatment with a a placebo gel, b Aloe ferox gel and c Aloe vera gel

Table 1 Effects of topical application of A. vera and A. ferox on $\operatorname{IgE}$ levels in mice suffering from atopic dermatitis

\begin{tabular}{llll}
\hline Treatment & $\begin{array}{l}\text { Number of mice } \\
\text { on treatment }\end{array}$ & $\begin{array}{l}\text { Mean IgE } \\
\text { concentration } \\
(\mathrm{ng} / \mathrm{ml})\end{array}$ & $\begin{array}{l}\text { Standard deviation } \\
\text { IgE concentration }\end{array}$ \\
\hline Placebo & 18 & 4356.183 & 361.186 \\
Aloe ferox & 18 & $4356.183^{*}$ & 361.186 \\
Aloe vera & 20 & $4105.793^{*}$ & 294.297 \\
\hline
\end{tabular}

$* p<0.0001$

Although the majority of $\mathrm{AD}$ patient are still being treated with topical corticosteroids as the first line of treatment, there is still an pressing requirement for other anti-inflammatory drugs that can be used as an alternative to, or as an intermittent or alternating therapy during longterm treatment with topical corticosteroids because of the concern regarding long-term side effects of corticosteroid therapy (Charman et al. 2000; Henge et al. 2006).

The use of A. vera as an herbal medicine has long been documented to have anti-inflammatory, anti-oxidant, anticancer, wound-healing, anti-ageing and anti-diabetic properties, whereas A. ferox extracts have been described to possess anti-inflammatory, anti-bacterial and anti-fungal properties (Reynolds and Dweck 1999). Cock (2015) concluded that the anti-inflammatory effects of the Aloe species are possible due to their anti-oxidant properties. Kim et al. (2010) investigated the effects of extracts of $A$. ferox and $S$. radix, administered p.o. at either 0.8 or $50 \mathrm{mg} / \mathrm{kg}$ in $\mathrm{AD}$ induced in mice. Both these treatments suppressed Il-5 levels but had no effect on IgE levels.

The present study was undertaken to assess the efficacy of the topical application of A. ferox and A. vera gel in 2,4dinitrochlorobenzene (DNCB)-induced $\mathrm{AD}$ in mice. Macroscopic evaluation indicated that this model responded favourably to both A. ferox and A. vera treatments, with $A$. ferox treatment slightly superior to $A$. vera treatment. Furthermore, it was also found that these two treatments decreased the levels of IgE, possibly due to an inhibition of Th2 cell activation.
Histological analysis of the control group indicated abnormalities associated with $\mathrm{AD}$ such as ulceration as well as hyperkeratosis of the skin and an absence of skin structures such as hair follicles and sweat glands. This was also observed in the A. ferox and A. vera treatment groups, but to a lesser extent.

Further investigations need to be directed towards identifying target immune cells for Aloe-mediated alleviation of atopic dermatitis-like immunologic and skin alterations.

\section{Conclusion}

In this study, we identified the inhibitory effects of the gels of both A. ferox and A. vera, applied topically, on the symptoms as well as IgE levels of a mouse model of AD indicating that these gels may suppress chronic $\mathrm{AD}$ by a selective reduction of the Th2 response. This is in contrast with findings by Kim et al. (2010) who found that systemically applied $A$. vera gel had no effect on either IgE levels or the symptoms of spontaneous atopic dermatitis in mice. Furthermore, it was shown that the gel of A. ferox is superior to that of $A$. vera in this regard. These gels may be safe and useful alternatives for the treatment of patients suffering from recurring chronic $\mathrm{AD}$.

Acknowledgments This study was supported by a Grant from the House of Aloes, Albertinia, South Africa.

\section{References}

Arellano FM, Wentworth CE, Arana A, Fernandez C et al (2007) Risk of lymphoma following exposure to calcineurin inhibitors and topical steroids in patients with atopic dermatitis. J Invest Dermatol 127:808-816

Ashcroft DM (2005) Efficacy and tolerability of topical pimecrolimus and tacrolimus in the treatment of atopic dermatitis: metaanalysis of randomised controlled trials. Brit Med J 330:516-522

Beltrani VS (1999) The clinical spectrum of atopic dermatitis. J Allergy Clin Immun 104:587-598 
Capasso F, Borrelli F, Capasso R (1998) Aloe and its therapeutic use. Phytother Res 12:124-127

Charman CR, Morris AD, Williams HC (2000) Topical corticosteroid phobia in patients with atopic eczema. Brit $\mathrm{J}$ Dermatol 142:931-936

Chen W, Van Wyk B-E, Vermaak I et al (2012) Cape aloes: a review of the phytochemistry, pharmacology and commersialisation of Aloe ferox. Phytochem Lett 5:1-12

Cock IE (2015) The genus aloe: phytochemistry and therapeutic uses including treatments for gastrointestinal conditions and chronic inflammation. Drug Res 70:179-235

Duke JA (1997) The green pharmacy. Rodale Press, Emmaus

Ellis C, Luger T, Abeck D et al (2003) International consensus conference on atopic dermatitis II (ICCAD II): clinical update and current treatment strategies. Brit J Dermatol 148:3-10

Eshun K, He Q (2004) Aloe vera: a valuable ingredient for the food, pharmaceutical and cosmetic industries-a review. Crit Rev Food Sci 44:91-96

Henge UR, Ruszicka T, Schwartz RA et al (2006) Adverse effects of topical glucocorticosteroids. J Am Acad Dermatol 54:1-15

Kay GG (2000) The effects of antihistamines on cognition and performance. J Allergy Clin Immunol 105(6):S622-S625
Kim J, Lee I, Park S, Choue R (2010) Effects of Scutellariae radix and Aloe vera gel extracts on immunoglobulin $\mathrm{E}$ and cytokine levels in atopic dermatitis $\mathrm{NC} / \mathrm{Nga}$ mice. J Ethnopharmacol 132(2):529-532

Lee S-J, Oh S-G, Seo S-W et al (2007) Oral administration of Astragalus membranaceus inhibits the development of DNFBinduced dermatitis in NC/Nga mice. Biol Pharm Bull 30:1468-1471

Leund DY (1997) Atopic dermatitis: immunobiology and treatment with immune modulators. Clin Exp Immunol 107(1):25-30

Reynolds T, Dweck AC (1999) A ferox extracts have been described to possess anti-inflammatory, anti-bacterial and anti-fungal properties plus increased wound healing. J Ethnopharmacol 28(1-3):3-37

Sidbury R, Hanifin JM (2000) Systemic therapy of atopic dermatitis. Clin Exp Dermatol 25:559-566

Stephen P, Stone SP, Muller SA, Muller MD, Gerald J, Gleich MD (1973) IgE levels in atopic dermatitis. Arch Dermatol 108(6):806-811 